\title{
Internal Carotid Artery Hypoplasia: A New Clinical Feature in Pseudoxanthoma Elasticum
}

\author{
Loukman Omarjee, ${ }^{\mathrm{a}, \mathrm{b}, \mathrm{c}}$ Jacques-Olivier Fortrat, ${ }^{\mathrm{c}}$ Antoine Larralde, ${ }^{\mathrm{d}}$ Estelle Le Pabic, ${ }^{\mathrm{e}}$ \\ Gilles Kauffenstein, ${ }^{\mathrm{b}, \mathrm{c}}$ Maxence Laot, ${ }^{\mathrm{d}}$ Nastassia Navasiolava, ${ }^{\mathrm{b}, \mathrm{c}}$ Pierre-Jean Mention, ${ }^{\mathrm{f}}$ \\ Juan Luis Carrillo Linares, ${ }^{\mathrm{g}}$ Pedro Valdivielso, ${ }^{\mathrm{g}}$ Olivier M. Vanakker, ${ }^{\mathrm{h}}$ Guillaume Mahé, ${ }^{\mathrm{a}}$ \\ Ludovic Martin, ${ }^{\mathrm{b}, \mathrm{c}}$ Georges Lefthériotis ${ }^{\mathrm{b}, \mathrm{i}}$ \\ aVascular Medicine Department, INSERM CIC1414, Rennes, France \\ bPXE Reference Center, University Hospital of Angers, Angers, France \\ 'MitoVasc Institute, UMR CNRS 6015-UMR INSERM 1083, Angers University, Angers, France \\ ${ }^{\mathrm{d}}$ Radiology and Medical Imaging Department, Rennes University Hospital, Rennes, France \\ 'Department of Biostatistics and Methodology, Rennes University Hospital, Rennes, France \\ fDepartment of Nuclear Medicine, Angers University Hospital, Angers, France \\ IInternal Medicine Unit, Hospital Virgen de la Victoria and Instituto de Investigación Biomédica (IBIMA), Malaga, Spain \\ ${ }^{\text {h}}$ Center for Medical Genetics, Ghent University Hospital, Ghent, Belgium \\ 'Department of Physiology and Vascular Investigations, University Hospital, Nice, France
}

Dear Sir:

Pseudoxanthoma elasticum (PXE) is an inherited metabolic disease characterized by elastic fiber fragmentation and ectopic calcification in various tissues. ${ }^{1}$ Cerebrovascular abnormalities have been sporadically reported in PXE. ${ }^{2}$ The aims of this study are: (1) to investigate the prevalence of internal carotid artery hypoplasia (ICAH) in a PXE patient cohort by comparison with a non-PXE patient cohort; (2) to evaluate the prevalence of intracranial aneurysms (IAs) or arterial malformations (AMs) in ICAH PXE patients; and (3) to investigate the prevalence of stroke in ICAH PXE versus non-ICAH PXE patients.

We retrospectively compared 151 PXE patients from the French PXE cohort (National Reference Center for PXE at Angers University Hospital) to 402 non-PXE patients. ICAH was defined as diameter $<3 \mathrm{~mm}$ as assessed by ultrasound imaging and confirmed by computed tomography angiography imaging. Stroke was defined as an acute neurological event with focal symptoms and signs lasting $\geq 24$ hours consistent with focal cerebral ischemia and confirmed by cerebral imaging. Patients were deemed to have experienced a stroke once this information was retrieved from the medical record database.

Continuous variables were described as mean \pm standard de- viation, and categorical variables were expressed as numbers and percentages. Chi-square test was used for categorical variables. In order to take into account possible heterogeneity between PXE- and non-PXE patients at baseline, $P$-value adjustments $\left(P_{\text {adjusted }}\right)$ were made using multivariate logistic regression analysis (MLRA) with body mass index, Framingham-Laurier scores, common carotid artery diameter and ankle-brachial-index as explanatory variables of ICAH, and the same variables in addition to internal carotid artery (ICA) diameter and mean resistive index as explanatory variables of stroke. Statistical analysis was performed using SAS version 9.4 software (SAS Institute, Cary, NC, USA). A significance threshold of 0.05 was applied to all of the statistical tests.

In this study, rules of ethics were followed for all patients in accordance with the Declaration of Helsinki of 2008. All patients provided informed written consent and the study was approved by our local ethics committee (CPP Ouest II, Angers, France).

Thirteen PXE patients and one non-PXE patient ( $8.6 \%$ vs. $0.2 \%, P<0.0001)$ presented with ICAH (Figures 1 and 2). MLRA indicated that ICAH was associated with PXE (odds ratio [OR], 7.44; 95\% confidence interval [CI], 1.20 to $46.25 ; P_{\text {adjusted }}$ $=0.0314)$. IA and AM were found in 38.5\% (5/13) of ICAH PXE

Copyright (C) 2019 Korean Stroke Society

This is an Open Access article distributed under the terms of the Creative Commons Attribution Non-Commercial License (http://creativecommons.org/licenses/by-nc/4.0/) which permits unrestricted non-commercial use, distribution, and reproduction in any medium, provided the original work is properly cited. 


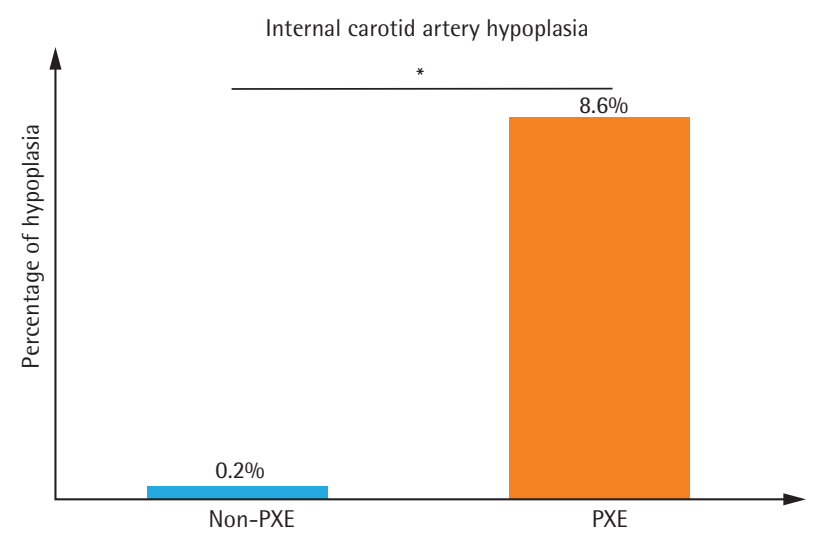

Figure 1. Prevalence of internal carotid artery hypoplasia (ICAH) in one cohort of pseudoxanthoma elasticum (PXE) patients and another cohort of non-PXE patients. ${ }^{*} P<0.0001$.

patients (Figure 2B). No statistically significant difference in stroke prevalence between ICAH and non-ICAH PXE patients was observed ( $23.1 \%$ vs. $7.2 \%, P=0.0861)$ confirmed by MLRA where stroke prevalence was not statistically significant between PXE and non-PXE patients $(\mathrm{OR}, 1.73 ; 95 \% \mathrm{Cl}, 0.50$ to 6.01; $P_{\text {adjusted }}=0.3853$ ).

The present study shows that ICAH is common in patients with PXE and is frequently associated with IA but does not increase the risk of stroke. The typical appearance of ICAH encountered in our PXE patients differed from that of atherosclerotic lesions or medial calcification and was devoid of echogenic densification or any lesions or irregularities suggestive of fibrodysplasia. Prevalence of ICAH (8.6\%) was strikingly higher than that found in non-PXE patients $(0.2 \%)$. The results we obtained from non-PXE patients are consistent with those documented in the general population where prevalence of unilateral or bilateral ICAH is reportedly below $0.1 \% .^{3}$ In the general population ICAH is bilateral in $40 \%$, unilateral right-sided in $40 \%$ and unilateral left-sided in $20 \%$ of cases. ${ }^{3}$ This distribution echoes our findings (31\% of bilateral, 38\% of left-sided, and $31 \%$ of right-sided ICAH in 13 PXE patients with ICAH), suggesting similar mechanisms despite higher incidence in PXE patients.

In our study, we found that the carotid canal match to the ICA diameter suggesting an impaired developmental process. Indeed, given that the carotid canals in the skull base form secondary to the presence of the embryonic ICA, asymmetric diameters of the two carotid canals imply a developmental defect of the narrow internal carotid artery. ${ }^{4}$ Computed tomography imaging of the skull base is the best means of studying the carotid canal and has become the main tool for diagnosing ICAH. ${ }^{4}$ From a pathophysiological point of view, ICAH has been

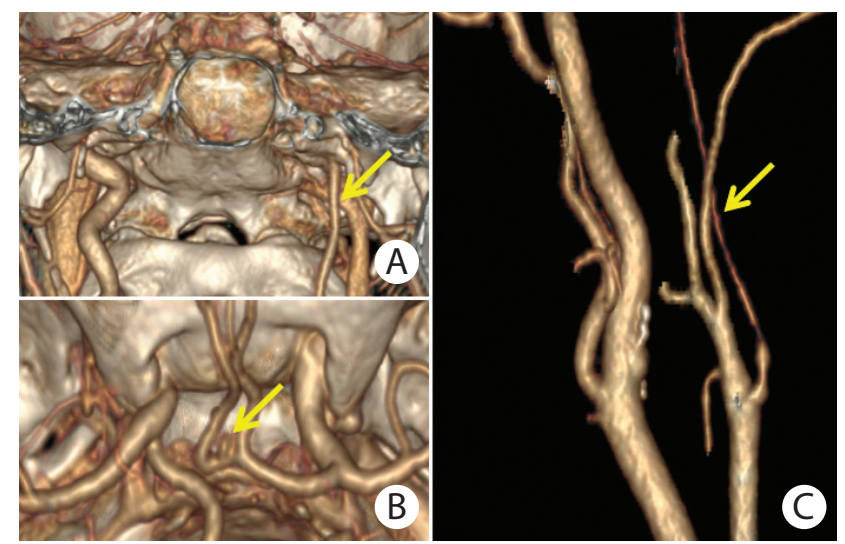

Figure 2. (A) Computed tomography angiography (CTA) with 3D volume rendering reconstruction of unilateral left internal carotid artery hypoplasia (ICAH) in a female pseudoxanthoma elasticum (PXE) patient in coronal plane (yellow arrow). (B) Upper view of small aneurysm of anterior communicating artery (yellow arrow) with visualization of circle of Willis and base of skull. (C) Reconstructed CTA image of internal carotid artery in a female PXE patient with left ICAH (yellow arrow).

observed in association with various conditions, such as NF2, 5,6 polycystic kidney disease ${ }^{7}$ (PKD) and Klippel-Trenaunay syndrome, $^{8}$ but its etiology is largely unknown. Merlin and PKD protein mutations cause NF2 and PKD, respectively., ${ }^{9,10}$ These proteins are implicated in endothelial cell mechanostransduction., ${ }^{9,10}$ They contribute to vascular morphogenesis by bloodflow sensing. ${ }^{9,10}$

ICAH in PXE displays unique morphological characteristics that differ from the clinical features usually observed in other vascular diseases involving stenosis of the ICA. The latter is encountered in several acquired diseases such as arteriosclerosis, ${ }^{11}$ large vessel vasculitis, ${ }^{12}$ fibromuscular dysplasia, ${ }^{13}$ intimal dissection, ${ }^{14}$ and moyamoya disease. ${ }^{15}$ ICAH may be caused by abnormal signaling between the extracellular matrix and vascular cells. Indeed elastic fibers, which are fragmented in PXE, are a key regulator of vascular wall development. ${ }^{16}$ Patients with inherited elastin defects develop segmental stenosis of the internal lumen in various vascular beds which differs from ICAH. ${ }^{17}$ Furthermore, elastin matrix deposition in the arterial wall during late fetal development is essential for normal arterial morphogenesis. ${ }^{18}$ We cannot, however, rule out the possibility that abnormalities in the fibroblasts of PXE patients might be instrumental in the pathogenesis of ICAH. ${ }^{18}$ Nevertheless, specific ATP-binding cassette sub-family $\mathrm{C}$ member 6 (ABCC6) mutations could not be linked to ICAH-patients because no phenotype-genotype correlation was observed in ICAH PXE patients in this study (data not shown). Furthermore, ICAH should be treated as an additional phenotypic expression of PXE. In our study we observed $38.5 \%$ of IA and AM in ICAH PXE pa- 
tients. Hence patients with ICAH should be screened for potential IA in the circle of Willis or AM, since the incidence of aneurysm is $24 \%$ to $34 \%$ in these patients compared to $2 \%$ to $4 \%$ in the general population. ${ }^{3}$

ICAH was associated with hemorrhagic stroke in $23.1 \%$ of cases. In non-ICAH PXE patients, $7.2 \%$ had a history of ischemic stroke. No significant association was found between ICAH and stroke. In the general population, narrowing of the carotid lumen diameter results mainly from atherosclerosis and contributes to a higher risk of recurrent ischemic stroke. ${ }^{19}$

Furthermore, stroke prevalence of 8.6\% in our cohort of PXE patients (including ICAH and non-ICAH) correlates with a recent study ${ }^{20}$ which reports $8 \%$ of strokes in 178 PXE patients from a Dutch cohort. Prevalence of stroke in the general population of a similar age approximates $3 \%{ }_{1}^{21}$ reflecting an increased risk of stroke in PXE patients.

ICAH is common in PXE patients and vascular physicians might test for this new feature during vascular assessment. Furthermore, this study suggests that PXE patients might be screened for ICAH. In all cases where ICAH is present, patients might undergo cerebral imaging to identify any aneurysms.

\section{References}

1. Lefthériotis $G$, Omarjee $L$, Le Saux 0 , Henrion $D$, Abraham $P_{1}$

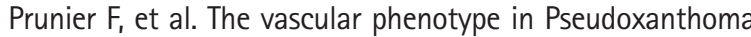
elasticum and related disorders: contribution of a genetic disease to the understanding of vascular calcification. Front Genet 2013;4:4.

2. van den Berg JS, Hennekam RC, Cruysberg JR, Steijlen PM, Swart J, Tijmes N, et al. Prevalence of symptomatic intracranial aneurysm and ischaemic stroke in pseudoxanthoma elasticum. Cerebrovasc Dis 2000;10:315-319.

3. Taşar $M$, Yetişer $S$, Taşar $A$, Uğurel $S$, Gönül $E$, Sağlam $M$. Congenital absence or hypoplasia of the carotid artery: radioclinical issues. Am J Otolaryngol 2004;25:339-349.

4. Osborn RE, Mojtahedi S, Hay TC, DeWitt JD. Internal carotid artery hypoplasia. Comput Radiol 1986;10:283-287.

5. Chen MC, Liu HM, Huang KM. Agenesis of the internal carotid artery associated with neurofibromatosis type II. AJNR Am J Neuroradiol 1994;15:1184-1186.

6. Wali AR, Santiago-Dieppa DR, Steinberg JA, Alattar A, Cheung VJ, Modir R, et al. Hypoplastic internal carotid artery co-presenting with neurofibromatosis and intracranial masses. Cureus 2016;8:e750.

7. Afifi AK, Godersky JC, Menezes A, Smoker WR, Bell WE, Jacoby CG. Cerebral hemiatrophy, hypoplasia of internal carotid artery, and intracranial aneurysm. A rare association occur- ring in an infant. Arch Neurol 1987;44:232-235.

8. Goldstein SJ, Lee C, Young AB, Guidry GJ. Aplasia of the cervical internal carotid artery and malformation of the circle of Willis associated with Klippel-Trenaunay syndrome. Case report. J Neurosurg 1984;61:786-789.

9. Wong HK, Shimizu A, Kirkpatrick ND, Garkavtsev I, Chan AW,

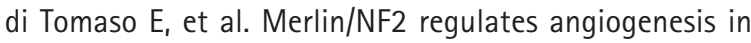
schwannomas through a Rac1/semaphorin 3F-dependent mechanism. Neoplasia 2012;14:84-94.

10. Forman JR, Qamar S, Paci E, Sandford RN, Clarke J. The remarkable mechanical strength of polycystin-1 supports a direct role in mechanotransduction. J Mol Biol 2005;349:861871.

11. Casadei A, Floreani M, Catalini R, Serra C, Assanti AP, Conci P. Sonographic characteristics of carotid artery plaques: implications for follow-up planning? J Ultrasound 2012;15:151-157.

12. Giordana $P$, Baqué-Juston $M C$, Jeandel PY, Mondot $L$, Hirlemann J, Padovani B, et al. Contrast-enhanced ultrasound of carotid artery wall in Takayasu disease: first evidence of application in diagnosis and monitoring of response to treatment. Circulation 2011;124:245-247.

13. Arning C, Grzyska U. Color Doppler imaging of cervicocephalic fibromuscular dysplasia. Cardiovasc Ultrasound 2004;2:7.

14. Chandra A, Suliman A, Angle N. Spontaneous dissection of the carotid and vertebral arteries: the 10-year UCSD experience. Ann Vasc Surg 2007;21:178-185.

15. Cali RL, Berg R, Rama K. Bilateral internal carotid artery agenesis: a case study and review of the literature. Surgery 1993;113:227-233.

16. Karnik SK, Brooke BS, Bayes-Genis A, Sorensen L, Wythe JD, Schwartz RS, et al. A critical role for elastin signaling in vascular morphogenesis and disease. Development 2003;130:411-423.

17. Pober BR, Johnson M, Urban Z. Mechanisms and treatment of cardiovascular disease in Williams-Beuren syndrome. $J$ Clin Invest 2008;118:1606-1615.

18. Quaglino D, Boraldi F, Annovi G, Ronchetti I. The multifaceted complexity of genetic diseases: a lesson from pseudoxanthoma elasticum. In: Ikehara K. Advances in the Study of Genetic Disorders. Rijeka, HR: Intech, 2011;289-318.

19. Johansson $E_{1}$ Cuadrado-Godia $E_{1}$ Hayden D, Bjellerup J, Ois A, Roquer J, et al. Recurrent stroke in symptomatic carotid stenosis awaiting revascularization: a pooled analysis. Neurology 2016;86:498-504.

20. Kauw F, Kranenburg G, Kappelle $\sqcup$, Hendrikse J, Koek HL, Visseren FL, et al. Cerebral disease in a nationwide Dutch pseudoxanthoma elasticum cohort with a systematic review of the literature. J Neurol Sci 2017;373:167-172.

21. Benjamin EJ, Virani SS, Callaway CW, Chamberlain AM, 
Chang AR, Cheng $S$, et al. Heart disease and stroke statistics-2018 update: a report from the American Heart Association. Circulation 2018;137:e67-e492.
Correspondence: Loukman Omarjee

Vascular Medicine and Investigations Department, Hôpital Pontchaillou, Rennes University Hospital, 2 rue Henri Le Guilloux, Rennes 35033, France

Tel: +33-2-9928-4321

Fax: +33-2-9928-4364

E-mail: loukmano@yahoo.fr

Received: September 20, 2018

Revised: October 29, 2018

Accepted: November 1, 2018

The authors wish to thank "PXE France" patients' association for its encouragement of our work and Mrs Hazel Chaouch for the formatting of the article and English language correction. The authors wish to thank Mrs Hélène Humeau, Mrs Isabelle Albertini, Mrs Stéphanie Marechal-Girault, Mrs Marion Mounier, Mrs Karine Unger, and Mr Théo Antunes for their technical assistance in the success of this study.

The authors have no financial conflicts of interest. 